\title{
A EXPERIÊNCIA DA INFÂNCIA ENTRE OS DILEMAS DA EDUCAÇÃO MODERNA E O EMPOBRECIMENTO DO TRABALHO DOCENTE
}

\author{
LA EXPERIENCIA DE LA INFANCIA ENTRE LOS DILEMAS DE LA EDUCACIÓN \\ MODERNA Y EL EMPOBRECIMIENTO DEL TRABAJO DOCENTE
}

\section{EXPERIENCE OF CHILDHOOD BETWEEN MODERN EDUCATION DILEMMAS AND THE IMPOVERISHMENT OF THE TEACHER WORK}

\author{
Anilde Tombolato Tavares da SILVA ${ }^{1}$ \\ Cândida Alayde de Carvalho BITTENCOURT ${ }^{2}$ \\ Marta Regina Furlan de OLIVEIRA ${ }^{3}$
}

RESUMO: Este texto busca refletir os dilemas da educação moderna, da experiência da infância e o empobrecimento do trabalho docente à luz de Theodor Adorno, Walter Benjamin, Jean-François Lyotard, Giorgio Agamben, Fernando Barcena e Michel Foucault, entre outros. $\mathrm{O}$ texto se justifica uma vez que o mundo moderno transformou-se em mera atividade repetidora, incapaz de traduzir-se em experiências narráveis. O desafio é o de restituir a possibilidade da experiência reflexiva entre os saberes e práticas educacionais, a fim de contribuir para uma ação do pensar que provenha da experiência da infância e que provoque uma atitude crítica para discutir as consequências do processo de empobrecimento do trabalho docente no contexto vigente.

PALAVRAS-CHAVE: Educação. Trabalho docente. Experiência da infância. Modernidade.

RESUMEN: El texto busca reflexionar sobre los dilemas de la educación moderna, de la experiencia de la infancia y el empobrecimiento del trabajo docente a la luz de Theodor Adorno, Walter Benjamin, Jean-François Lyotard, Giorgio Agamben, Fernando Barcena y Michel Foucault, entre otros. El texto se justifica puesto que el mundo moderno se convirtió en una simple actividad repetidora, incapaz de traducirse en experiencias narrables. El reto es restituir a la posibilidad de la experiencia reflexiva entre los saberes y prácticas educacionales, con el fin de contribuir para una acción del pensar que venga de la experiencia de la infancia y que provoque una actitud crítica para discutir las consecuencias del proceso de empobrecimiento del trabajo docente en el contexto vigente.

PALABRAS CLAVE: Educación. Trabajo docente. Experiencia de la infancia. Modernidad.

${ }^{1}$ Universidade Estadual de Londrina (UEL), Londrina - PR - Brasil. Docente do Departamento de Educação. Pósdoutorado em Educação. ORCID: https://orcid.org/0000-0001-8391-880X. Lattes: http://lattes.cnpq.br/3570231779830818. E-mail: anildetombolato@gmail.com

${ }^{2}$ Universidade Estadual de Londrina (UEL), Londrina - PR - Brasil. Docente da área de formação de professores de Arte. Pós-doutorado em Educação. ORCID: https://orcid.org/0000-0001-9299-146X. Lattes: http://lattes.cnpq.br/8604831792425650. E-mail: candida.carvalho@uel.br

${ }^{3}$ Universidade Estadual de Londrina (UEL), Londrina - PR - Brasil. Docente do programa de pós-graduação em Educação. Pós-doutorado em Educação. ORCID: http://orcid.org/0000-0003-2146-2557. Lattes: http://lattes.cnpq.br/ 8423465824507075. E-mail: marta.furlan@yahoo.com.br

RIAEE - Revista Ibero-Americana de Estudos em Educação, Araraquara, v. 14, n. esp. 4, p. 2032-2045, dez., 2019. E-ISSN: $1982-5587$. DOI: https://doi.org/10.21723/riaee.v14iesp.4.12926 
ABSTRACT: This text seeks to reflect the dilemmas of modern education, the experience of childhood and the impoverishment of teacher work in the light of Theodor Adorno, Walter Benjamin, Jean-François Lyotard; Giorgio Agamben, Fernando Barcena and Michel Foucault, among others. The text is justified since the modern world has turned into mere repeating activity, unable to translate into tellable experiences. The challenge is to restore the possibility of reflective experience between knowledge and educational practices, in order to contribute to a thinking action that comes from childhood experience and provokes a critical attitude to discuss the consequences of the process of impoverishment of teacher work in the current context.

KEYWORDS: Education. Teacher work. Experience of childhood. Modernity.

\section{Introdução}

Os caminhos que se pode percorrer para falar da relação entre a expropriação da experiência formativa e sua simplificação na modernidade são os mais diversos e também complexos. Escolhemos nos enveredar por aquele que de alguma forma temos mais proximidade, nos deixam mais seguros e nos fascinam: a infância e a formação de professores. Um fascínio que vem acompanhado de um inquietamento que traz a sensação de uma impotência intelectual que intriga: compreender se é ainda possível buscar a experiência da infância em todo seu sentido no campo da prática educativa, contrapondo-se ao empobrecimento do trabalho docente.

Nesta escolha, encontramos apoio na perspectiva teórica dos filósofos contemporâneos como Theodor Adorno, Walter Benjamin, Jean-François Lyotard, Giorgio Agamben, Fernando Barcena, entre outros que nos trazem, cada um a sua maneira, e dentro de suas particularidades e realidades vivenciadas, pontos convergentes para pensar esta questão; assim como na possibilidade de pensar a experiência como contraponto da nossa própria infância, como forma de resistência ao instituído e o empobrecimento da atividade docente. É uma reflexão do fazer pedagógico na atualidade, num encontro de elementos teóricos na base da filosofia contemporânea que nos permite refletir a expropriação da experiência formativa no processo do fazer pedagógico do professor que atua com a criança.

Consideramos relevante esclarecer que a experiência expropriada, empobrecida, é entendida por nós como forma de simplificação dos bens culturais, de sua transmissão e apropriação para tornar-se mera informação, referência sem sentido. Uma expropriação que resulta numa simplificação da atividade docente, que ao simplificar o complexo, distancia-se 
não só do seu próprio fazer, mas da própria experiência de infância, didatizando-a sem exigir nenhum esforço para compreendê-la.

Por meio da leitura e estudos dos textos dos autores que nos acompanham na trajetória teórica e reflexiva, podemos pensar que um dos caminhos que conduziu para este empobrecimento da experiência é, sem dúvida, o desenvolvimento da tecnologia e da propagação da indústria cultural no mundo moderno, que nos impõe um tempo acelerado e o interesse da sobrevivência imediata. Um processo que nos obriga a "não perder tempo", "andar depressa" e como consequência, traz a abreviação de nós mesmos como humanos e que nos empurra a uma sensação que vai se naturalizando na educação moderna, onde só resta ao professor o papel de "explicador" de saberes, sem a necessidade de ver a criança enquanto um ser pensante e ativo.

Por mais que a educação defenda a possibilidade para que tenhamos como meta o pensamento reflexivo e transformador, somos subjugados por esse processo naturalizado da contemporaneidade, que domina e expropria nossa capacidade criadora e reflexiva. $\mathrm{O}$ desafio foi o de restituir a possibilidade da experiência formativa e reflexiva entre os saberes e práticas escolares, em vistas a contribuir para uma prática de pensar que provenha da experiência da infância e provoque uma atitude crítica para discutir as consequências do processo de infantilização do fazer pedagógico na sociedade atual.

Esse processo acontece pelo discurso moderno e o exercício de poder conferido aos adultos, quando coloca a criança numa posição de dependência, em casa e na família com os pais ou os responsáveis, e na escola pelo vínculo professor-aluno. Essa barreira que separa crianças e adultos é que necessita ser revista - pois a partir dela criam-se redes de discursos sobre as crianças que as nomeiam, e ditam suas particularidades para um determinado tipo de sociedade - se quisermos crianças que ultrapassem a barreira da dependência e da heteronomia.

O pensamento reflexivo e criativo é elemento inerente e propulsor da atividade pedagógica, mas estamos envolvidos pelo deslumbramento do processo tecnológico e nos deixamos levar pela degeneração do pensamento reflexivo ameaçando o conteúdo ético do processo formativo em razão de sua determinação social. Fomos expropriados da possibilidade de experimentar e envolvidos por uma formação que privilegia um saber técnico em detrimento do saber filosófico e criativo do pensamento e da reflexão crítica sobre a educação. Expropriados do nosso pensar in-fante, da nossa própria experiência, somos impedidos de pensar o impensável. E assim, a atividade docente como toda a atividade do homem moderno, transforma-se em mera técnica ou aplicação de conhecimentos produzidos pelas ciências da educação, atendendo a necessidade social de aumento da eficiência, a demanda de qualificação RIAEE - Revista Ibero-Americana de Estudos em Educação, Araraquara, v. 14, n. esp. 4, p. 2032-2045, dez., 2019. E-ISSN: 1982-5587. DOI: https://doi.org/10.21723/riaee.v14iesp.4.12926 
profissional e aos padrões de consumo. Mera atividade repetidora, incapaz de traduzir-se em experiências narráveis. Para Benjamin (1992, p. 28), a chegada nos tempos modernos foi extinguindo a capacidade do indivíduo de contar histórias, trocar experiências e se comunicar. O ensaio do autor inicia com a observação de que o "Narrador" não consegue ser plenamente eficaz na sua experiência de narrar, "é cada vez mais raro encontrar pessoas que saibam narrar coisas com correção".

São os efeitos negativos de um processo formativo pautado meramente numa estratégia de "esclarecimento" da consciência sem considerar as condições concretas desta formação social como apropriação de conhecimentos técnicos. A formação vai dissolvendo-se como experiência formativa silenciada e esvaziada de conteúdos que se esgotam na própria relação formal com o conhecimento, impedindo, assim, que forneçam ao professor formas para refletir sobre os problemas que enfrenta e para encontrar meios de solucioná-los ou traduzi-los e narrálos como experiência.

\section{Experiência da Infância Aprisionada}

A noção moderna de infância que foi incorporada nas políticas públicas, nos discursos educacionais e para dentro dos muros da escola, esteve associada à produção de novos modos educação para as crianças, voltada para a institucionalização delas. Estes discursos, estes raciocínios e estas novas posições de sujeito referidas aos infantis - estes esquemas de racionalidade -, nada mais são do que sistemas de ideias que permitiram pensar diferentemente o que é ser criança e introduziram, ao mesmo tempo, novos aparatos para seu controle e regulação.

Controle e regulação aqui entendidos como governo dentro da ideia foucaultiana da possibilidade de "estruturar o eventual campo de ação dos outros" (FOUCAULT, 1995b, p. 244), como resultado da vontade que alguns têm de atuar sobre a ação alheia, isto é, onde o governo das crianças precisa ser exercido desde a mais tenra infância numa paisagem social que a partir da Revolução Industrial vem consolidar novos arranjos familiares e novas exigências às mulheres e crianças, que se voltam ao trabalho produtivo. Desta forma, a criação de instituições específicas para o atendimento à infância vai se configurando como instrumental ao projeto de governo das populações, e a escola passou a exercer esta nova tarefa.

A educação institucionalizada vai se constituir numa estratégia privilegiada de disciplinamento das populações desde a mais tenra idade, fazendo a conexão entre o indivíduo 
e a sociedade. Desde a fase inicial e média da idade moderna, ela foi transformada numa dimensão do que Foucault (1995a) chamou "o grande confinamento", juntamente com o surgimento de prisões e hospícios para fins de "correção e coerção moral”. Como o insano e o criminoso, entendia-se que a criança precisava ser moldada, "num corpo dócil que pode ser subjugado, usado, transformado e melhorado". Isto nos remete às relações que não se encontram no objeto, não definem sua constituição interna, mas através das narrativas devem moldar as maneiras de constituir o mundo, de compreendê-lo e de falar sobre ele.

Precisamos compreender que a infância descrita historicamente nas práticas, nos discursos, nas categorias que servem para circunscrevê-la, nasce entre os adultos e tem sempre uma referência que é neles centrada como um devir ser: ou seja, a partir da própria negação da infância, colocando-a como uma fase passageira para alcançar à pretensa "adultez" racional. Assim, torna-se fácil perceber porque as crianças são descritas como imaturas, incompletas, desprotegidas e como seres moldáveis. As definições de criança e de infância são sempre relacionadas e referidas ao outro, o adulto. Seu significado varia de acordo com o tempo, com a autoridade de quem fala.

O assim chamado "sentimento de infância" é um fenômeno cultural próprio do nosso tempo. Um produto social bastante característico dos últimos três a quatro séculos. Portanto, os significados atribuídos à infância são resultados de um processo de construção social, dependem de um conjunto de possibilidades que se conjugam em determinado momento da história, são organizados socialmente e sustentados por discursos nem sempre homogêneos e em perene transformação. São modelos no interior de relações de poder e representam interesses manifestos pela necessidade histórica da sociedade que os engendram.

A invenção do sujeito infantil como sujeito autônomo, livre, sensível, percebido principalmente como fonte de conhecimento e de ação moral e política é uma tarefa sempre ameaçada e incompleta, onde os ideais modernos necessitam reafirmar-se constantemente. É por esta razão que se constroem narrativas capazes de reafirmar tais características e comportamentos, e assim constitui-se também "uma experiência tal que os indivíduos (são) levados a reconhecerem-se como sujeitos" (FOUCAULT, 1998, p. 10).

A visão como dependência, com crianças gradualmente conquistando sua autonomia moral, construindo experiência; a infância como um momento privilegiado, que representa o que de mais puro e bom existe na sociedade, como um ideal de perfeição, também constitui a orientação predominante do senso comum e se apropria dos discursos presentes na legislação da educação infantil. São concepções que estão de certa forma tão arraigadas e naturalizadas 
que deixam pouco espaço para que percebamos outra forma de pensar a infância ou de refletir sobre os pressupostos que vieram a constituí-la desta forma.

O que caracteriza as teorias pedagógicas que se elaboram dentro de uma perspectiva moderna é que elas se dirigem a uma infância tomada como normal e natural e na qual as crianças são posicionadas como aprendizes, como seres pensantes e racionais que precisam ser formadas em sujeitos dóceis e obedientes às leis (im)postas socialmente.

A ideia de "criança natural" tem dois desdobramentos que estão ainda hoje muito presentes nas nossas concepções de infância: o da criança raciocinante ou sujeito cognitivo e o da criança inocente. Ao primeiro vinculam-se aquelas interpretações que colocam o sujeito infantil na posição de aprendiz, com uma tendência natural à curiosidade, à investigação, à experimentação, com uma progressão em suas capacidades de raciocínio que se dá de forma "quase espontânea", ficando suposto que, quanto menos interferência, melhor. O segundo está associado à ideia de infância ameaçada, sempre a ponto de desaparecer e que precisa ser defendida das vicissitudes do mundo adulto.

A imagem do trabalho docente foi construindo-se nestes termos e ainda se fundamenta sobre os que necessitam de cuidados, de tratamento, de leis e de governamento porque possuem uma vida sem razão, sem consciência ou moral, nos desdobramentos de uma pedagogia na qual a infância é abordada como uma experiência singular a ser corrigida no processo formativo, subjugada a uma racionalidade subjetiva envolta na disciplina e na autoridade feita através da escola sob o jugo do professor. E assim a infância, pela via da educação, vai deixando seu traço de inferioridade para constituir-se como possibilidade. A escola e os professores deveriam colocar-se na contramão dessa constatação e se empenhar em buscar, em reconhecer e em elaborar a experiência, uma experiência em que a infância é imprescindível naquilo que o próprio prefixo in sugere, como algo da ordem do não-exprimível, do não-tratado discursivamente.

\section{Em Busca da Experiência da Infância.}

Nossa proposta é pensar na possibilidade da experiência da infância, indo ao encontro do que Walter Benjamin (1986; 1987) ressalta ao refletir sobre o modo como a criança constrói seu universo particular, dando outra significação ao cotidiano. Esse filósofo nos permite penetrar na magia da infância e descobrir com ela e por meio dela o mistério que emana do mundo dos objetos, pois são eles que alimentam a imaginação, dando conteúdo e forma aos segredos que revela. Assim, o filósofo mostra o quanto a criança emprega suas mágicas usando 
metamorfoses múltiplas, e que só ela dispõe desta capacidade de estabelecer semelhanças, incorporando às suas vivências uma mística que enfatiza sua sensibilidade pelo mundo dos objetos.

A concepção da experiência da infância com a qual estamos familiarizados em nosso tempo apresenta-se relacionada a uma etapa cronologicamente pré-determinada da vida do homem ou ainda caracterizada pelo estado de ingenuidade que independe da idade cronológica. Ideias alicerçadas pela necessidade humana de emancipação em que tanto uma quanto outra apresentam a infância como tempo de preparação, de proteção, de formação de sujeitos autônomos ou não, relacionada à esperança de um tempo melhor ou a uma experiência única e intransferível de infância.

Benjamin (1987) enfatiza a importância do jogo e da brincadeira de criança, que são carregados de comportamentos simbólicos e miméticos e não se limitam à imitação de pessoas, mas também de reelaboração e construção. As crianças não brincam apenas, mas transformamse. Não se limitam à encenação de serem professores, médicos, comerciantes, mamãe ou papai, mas também, transformam-se em trens, aviões, cavalos, gatos; ou seja, elas imitam o real sendo aquilo que sua imaginação realmente desejar - pessoa, animal ou coisa. O que se preserva é a linguagem, a narração e a imaginação criativa. Na experiência da criança não há limites rígidos entre imaginação e realidade; a forma peculiar com que a criança é capaz de lidar com o mundo objetivo nos permite uma compreensão mais profunda dos mecanismos da atividade criadora no homem. A imaginação da criança trabalha subvertendo a ordem estabelecida, pois impulsionada pelo desejo e pela paixão ela está sempre pronta para mostrar outra possibilidade de apreensão das coisas do mundo e da vida.

O filósofo destaca a dimensão cinematográfica que o olhar da criança revela e nos mostra, com grande sensibilidade e beleza, como os objetos se tornam para ela um reino de enigmas que podem ser decifrados em diversas direções. $O$ sensorial frequentemente empobrecido na experiência dos adultos torna-se para a criança uma realidade que anula a diferença entre objetos inanimados e seres vivos.

[...] as crianças são inclinadas de modo especial a procurar todo e qualquer lugar de trabalho onde visivelmente transcorre a atividade sobre as coisas. Sentem-se irresistivelmente atraídas pelo resíduo que surge na construção, no trabalho de jardinagem ou doméstico, na costura ou na marcenaria. Em produtos residuais reconhecem o rosto que o mundo das coisas volta exatamente para elas, e para elas unicamente. Neles, elas menos imitam as obras dos adultos do que põem materiais de espécie muito diferente, através daquilo que com eles aprontam no brinquedo, em uma nova, brusca relação 
entre si. Com isso as crianças formam para si seu mundo de coisas, um pequeno no grande, elas mesmas. (BENJAMIN, 1987, p. 18)

$\mathrm{Na}$ contramão do mundo adulto e da própria educação institucional, a criança busca outros aliados que são encontrados facilmente no mundo dos fenômenos. Apropriam-se com interesse e paixão de tudo o que é abandonado, aprendem assim a fazer história da história. Este fragmento de Benjamin nos deixa claro que a infância ocupa um lugar de destaque no restabelecimento da relação entre experiência e linguagem, suscitando uma reflexão tanto sobre os limites da linguagem quanto sobre o empobrecimento da experiência no mundo moderno. Parece querer nos mostrar que a educação institucional se priva de sua função, que é a indagação e o espírito crítico para assumir um saber fingido, e por isso a criança se lança a uma aprendizagem paralela, clandestina, em que o lúdico, o criativo, a arte, a imaginação, a experiência mantém uma estreita relação entre si.

Quando nos referimos à questão da experiência não podemos esquecer as precauções que devemos ter ao lidarmos com esta palavra, como nos recomenda Larossa (2004, p. 23-26), começando pela diferenciação que se deve fazer entre a experiência e experimento; ou seja, distanciá-la do seu sentido empírico, próprio das ciências experimentais. No sentido que queremos dar, experiência não é algo que pode ser calculado ou produzido tecnicamente, nem se deve dar à palavra experiência a conotação de dogma e pretensão à autoridade; pois a conotação pretendida aqui contrapõe-se a todo dogmatismo. A experiência, no sentido que queremos, deve ser pensada separada da prática, a partir do ponto de vista da paixão e da reflexão do sujeito sobre si mesmo, enquanto sujeito receptivo aberto e exposto à novidade.

Essa experiência nos leva à descoberta da nossa fragilidade, impotência e vulnerabilidade, que escapam do nosso controle e, portanto, temos que "evitar fazer da palavra experiência um conceito", mesmo quando somos solicitados a defini-la deste modo. A experiência, portanto, não é algo que todos têm que buscar ou deter, mas tomar a experiência como um modo de habitar o mundo no tempo e no espaço.

A crise da experiência foi instaurada e parece não ter mais possibilidades de reconstrução. O problema do empobrecimento da experiência, da capacidade de pensá-la e de narrá-la observada em nossos dias, consiste em um ponto importante da filosofia contemporânea. Benjamin (1986) foi um dos primeiros filósofos a diagnosticar esse problema e as suas consequências para a vida humana. Para o autor, a "cotação da experiência baixou", e numa análise mais apocalíptica traz sua sentença: "Uma miséria totalmente nova se abateu sobre o homem com este desenvolvimento monstruoso da técnica" (BENJAMIN, 1986, p. 195). É possível perceber esse processo no destino do homem moderno que, submetido a um ritmo RIAEE - Revista Ibero-Americana de Estudos em Educação, Araraquara, v. 14, n. esp. 4, p. 2032-2045, dez., 2019. E-ISSN: $1982-5587$. 
frenético e exposto a diferentes perigos, é obrigado a concentrar todas as suas energias na tarefa de proteger-se contra o choque, perdendo, assim, sua memória individual e coletiva. Seu comportamento reflexo desapropria-o da experiência.

Adorno (1992) parece ter radicalizado o diagnóstico de Benjamin ao relatar o retorno dos soldados após a segunda guerra. Para o filósofo alemão, os soldados retornavam sem nenhuma experiência a narrar, nem se empenhavam em significar ou conceitualizar as atrocidades cometidas pelo nazismo. Fizeram questão de esquecê-las e de se silenciar historicamente sobre esse mal que se abateu sobre a humanidade.

Fomos assim sendo expropriados da possibilidade de refletir sobre nosso presente. Fomos expropriados da experiência, como já nos disse Benjamim (1986), reforçado por Adorno (1992), ao qual enfatiza que "Já na guerra anterior, a inadequação do corpo humano às batalhas entre máquinas tornava impossível à experiência propriamente dita. Ninguém seria capaz de narrá-las, tal como ainda era a propósito das batalhas do general de artilharia Bonaparte" (ADORNO, 1992, p. 45). Essa expropriação persiste e se acentua cada vez mais no presente. As pessoas já não conseguem empenhar-se para analisar significativamente as atrocidades vividas ou cometidas que são transmitidas ao vivo para todo mundo via satélite nas televisões, em suas casas e, assim, confortavelmente no sofá da sala fecham-se os olhos. Os professores chegam para suas aulas como se a escola fosse um mundo à parte daquele em que por vezes nossas crianças são submetidas, como o abandono pelos pais, do abuso sexual, a violência, as drogas, enfim, um cenário de verdadeira desilusão, de vidas sem direitos nem sonhos. Assim, o professor se cala como um sintoma de incapacidade de reflexão crítica sobre a realidade que nos circunda, a reificação dos sentimentos e a frieza disseminada pela racionalidade técnica na modernidade.

Foi por meio de Agamben (2005) que o projeto benjaminiano parece caracterizar o problema do esfacelamento da experiência de um modo mais próximo ao que vivemos em nossos dias. $\mathrm{O}$ autor argumenta que não necessitamos presenciar nenhuma catástrofe ou guerra para percebermos a interdição da experiência, em nossos dias. Para o filósofo italiano, basta "a pacífica existência cotidiana em uma grande cidade" (AGAMBEN, 2005, p. 21). O silenciamento e a escuridão que nos impede de olhar através da impotência velada da submissão do nosso senso crítico, que se perdeu diante de uma realidade difusa que se deixa levar por uma onda que confunde a própria realidade.

Seguindo a análise de Agamben, podemos afirmar que nós, professores, somos empurrados para um cenário que vai se naturalizando na educação moderna, onde só nos resta o papel de "explicador" de saberes, pois ficamos limitados no processo de análise crítica do RIAEE - Revista Ibero-Americana de Estudos em Educação, Araraquara, v. 14, n. esp. 4, p. 2032-2045, dez., 2019. E-ISSN: 1982-5587. DOI: https://doi.org/10.21723/riaee.v14iesp.4.12926 
conhecimento adquirido. Por mais que a educação defenda as possibilidades para que tenhamos como meta o pensamento reflexivo e transformador, somos subjugados por esse processo naturalizador da vida moderna que domina e expropria nossa capacidade criadora e reflexiva. Nesse sentido, é imprescindível pensar que a educação deve ter outro significado que não o de passagem da menoridade ou da ausência de razão para a maioridade e da presença de razão; mas de promover a emancipação.

Já não há possibilidade de experiência na modernidade porque vivemos a vida como se não fosse nossa, sem entender o que se passa em nossa volta. O professor também age como se a atividade pedagógica não fosse dele, mas fabricada fora dele e, portanto, sem sentido, como algo que se vende no mercado como qualquer outra mercadoria. Daí a valorização no mercado editorial de livros didáticos e técnicos em que os dispositivos educacionais funcionam para dar a aparência do sentido que procuramos para nosso ofício e para nossa própria vida. Nossa carência é tanta, que seguimos qualquer um que vende um pouco de sentido. A experiência é destruída, ficando em seu lugar uma falsa sensação de experiência sem sentido, porque não sabemos o que se passa conosco. Estamos mudos porque não há mais palavras para elaborar a experiência. As palavras que temos são insignificantes, desvalorizadas e banais e, por isso, não se pode mais elaborar experiências. Se a experiência não adquire mais sentido em relação à vida do homem, esta não poderia mais chamar-se de experiência e, nem ser por isso, transmitida.

Se pensarmos sobretudo na experiência de ser professor ou de ser aluno, na experiência de ser criança e estar num ambiente escolar ou num espaço pedagógico, a experiência adquire um sentido de experiência "não vivida", pois aquilo que vivemos nesse ambiente não tem nada a ver conosco. É algo estranho tanto para nós quanto para a escola. No final do dia letivo tanto os professores quanto os alunos saem da escola mudos, sem ter o que dizer, contribuindo assim para os dispositivos que esfacelam a experiência e infantilizam seu fazer.

Desconsiderar a experiência da infância, enquanto uma condição de inacabamento, de limite e descontinuidade, é propiciar elementos para a materialização da própria “infantilização" da atividade docente, da simplificação da transmissão e apropriação dos bens culturais, tornando-se mera informação, referência sem sentido, efêmera, esvaziada de conteúdos formativos e sem qualquer significado ou atitude que pudesse contribuir na reflexão do sentido de sua própria atividade no presente. 


\section{Considerações finais}

Nosso principal interesse foi refletir sobre o processo de expropriação da experiência formativa imposto pelas contingências do mundo moderno e suas consequências para o empobrecimento do trabalho docente. Assim, munidos desta reflexão, buscar os caminhos que nos proporcionem um pensar a presença enigmática de uma experiência de infância que nos permite ser tocados por ela.

Posto isso, retomamos nossa questão inicial: Como buscar a infância, a experiência e seu sentido no campo da prática educativa, contrapondo-se ao empobrecimento do trabalho docente? Aquela que como a experiência da infância, se deixa levar rumo ao desconhecido para que a vejamos como novidade, aprendizado e experiência. Experiência de infância, enquanto aventura que junto aos filósofos que indicamos neste texto, possamos pensá-la de outra forma, não como racionalidade científica, mas pelo prisma pelo qual vem sendo tomada pela filosofia contemporânea, apreendida como algo singular, que não pode ser traduzida por palavras, mas pela rememoração, por aquilo que não está dado, nem tem resposta certa, mas nos faz ter atitude e nos obriga a uma ação que, muitas vezes, não tem uma única resposta, mas nos leva por caminhos diversos à sua procura.

A infância que encontra a experiência para quebrar o espelho que reflete apenas parte da realidade que impede a realização da verdadeira experiência da infância e do entendimento de que o verdadeiro saber é proporcionado por aquele que nos ensina a desaprender. É preciso estar disposto a abrir as portas para uma experiência múltipla de nós mesmos e deixar fluir o sentido da transformação, do educar, do instruir, do nutrir o espírito de discernimento e formar para a complexidade, situação em que homem e pensamento se constituem em parte desta complexificação do conhecimento e desta in-fância. "O pensamento está aqui, emaranhado em não-pensamento, tentando desemaranhar a língua perdida da infância” (LYOTARD, 1993, p. 123). Esta infância que Lyotard (1997) compreendeu como

[...] obediência a uma dívida, que se pode chamar de dívida de vida, do tempo, ou do acontecimento, dívida de ser aí pese a tudo, da que só o sentimento persistente, o respeito, pode salvar o adulto de ser só um sobrevivente, um vivente com sua aniquilação refreada (LYOTARD, 1997, p. 69).

Uma dívida que nos indica a valorização daquilo que fomos e somos enquanto acontecimento no mundo. Uma experiência singular e histórica, que diante de um pensar reflexivo e filosófico, nos coloca diante do começo que significou a nossa infância, reconhecendo, entre os labirintos e percalços, as possibilidades que ela nos deixou. A 
experiência da infância que defendemos é a que rompe com as supostas certezas que temos de nós mesmos, do mundo e da nossa própria infância. É a que nos permite combater a infantilização do trabalho docente que se desvaloriza e que empobrece a transmissão e apropriação dos bens culturais, com a didatização da complexidade do conhecimento transformado em mera informação.

Defrontamo-nos com uma educação que transforma a atividade pedagógica em mera técnica, ou aplicação do conhecimento produzido pelas ciências da educação, atendendo a necessidade do desenvolvimento da sociedade racional, da exigência do aumento da eficiência, e a demanda de qualificação profissional. Um caminho que coloca a infância como análoga à menoridade, negando a experiência que dela provém e a possibilidade de lançar novo olhar ao já instituído, empurrando-nos à substituição do caráter formativo reflexivo inerente à atividade educativa por um fazer mecânico que atende ao mercado e restringe o trabalho do professor à tarefa de adequar os meios certos aos fins dados, infantilizando-o. É uma tentativa de regulamentação superior ao exigido para a vida social, através do governamento da infância, como afirma Foucault, e pelo controle do Estado e das políticas públicas, a fim de ordenar o pensamento, disciplinar ou moldar qualquer gesto de rebeldia que possa ameaçar a racionalidade científica indubitável.

Isto implica um exercício contrário ao "pedagogismo", que tem, como uma de suas implicações, o excesso de infantilismo nas relações entre professor e aluno, e na sua didática. Uma presença marcante na nossa educação que prima por um diálogo, como uma simples troca de opiniões, e permite assistirmos, hoje, a uma espécie de morte do desejo de saber. É preciso refletir mais sobre esse fenômeno, pois é o maior obstáculo para uma ação educativa autêntica. Nesse sentido, a legitimação do saber deve ser política sem deixar de ser filosófica, pelo jogo da experimentação sobre a linguagem, nos lances enunciativos que mudam a regra do jogo presente no processo de produção e de transmissão de saber.

A atividade docente por intermédio de situações e narrativas precisa ter a função de afetar, de sensibilizar os envolvidos nesta experiência que estejam dispostos a dar-lhe significado. O significado se efetiva à medida que as pessoas aprendem e apreendem envolvidas numa experiência em que são afetadas por ela, seja pela palavra, seja pela imagem apresentada, ou por um gesto, mas que principalmente estejam dispostas a ir em busca da compreensão acerca de si ou da sua relação com o mundo.

Uma experiência profunda em que o professor afete e seja afetado e assim propicie meios de evitar a repetição da barbárie através da reflexão crítica e de resistência às suas causas e consequências no presente, contrapondo-se a um processo gerado pelo sistema que infantiliza RIAEE - Revista Ibero-Americana de Estudos em Educação, Araraquara, v. 14, n. esp. 4, p. 2032-2045, dez., 2019. E-ISSN: 1982-5587. 
sua atividade, para que ambos, professor e aluno, sejam afetados pela reflexão de seus limites, de sua finitude, de seu inacabamento, por uma infância constitutiva do devir humano, como uma forma de resistência a esse processo infantilizador, enfim, seja afetado pela sua infância.

Mesmo sem a exata dimensão da influência que exerce sobre a realidade vivida, a educação mostra-se como uma possibilidade aberta para a transformação, através da percepção de sua força possibilitadora de experiência. A emancipação apresenta-se como um sinal de reconhecimento daquilo que não devia ser assim, mas pode ser diferente; apresenta-se, portanto, como uma forma de resistência.

\section{REFERÊNCIAS}

AGAMBEN, G. Infância e História. Destruição da experiência e origem da história. Trad.: Henrique Burigo. Belo Horizonte: Ed. da UFMG, 2005.

ADORNO, T. W. Mínima moralia: reflexões a partir da vida danificada. São Paulo: Ática, 1992.

ADORNO, T. W. Educação e emancipação. São Paulo: Paz e Terra, 2003.

BARCENA, F. La esfinge muda. El aprendizaje del dolor después de Auschwitz. Barcelona: Anthropos, 2001.

BARCENA, F. El Delírio de lãs palabras. Ensayo para uma poética del comienzo. Barcelona: Herder, 2004.

BARCENA, F. La experiência reflexiva em educación. Barcelona: Paidós, 2005.

BENJAMIN, W. Documentos de cultura, documentos de barbárie: escritos escolhidos. São Paulo: Cultrix, 1986.

BENJAMIN, W. Rua de Mão Única. Obras Escolhidas, v. 2, São Paulo: Ed. Brasiliense, 1987.

BENJAMIN, W. Sobre Arte, Técnica, Linguagem e Política. Lisboa: Relógio d'Agua, 1992.

FOUCAUlT, M. As Palavras e as Coisas. São Paulo: Martins Fontes, 1992.

FOUCAULT, M. Verdade e Poder. In: FOUCAULT, M. Microfísica do poder. Rio de Janeiro: Graal, 1993, p. 1-14, 1993.

FOUCAULT, M. O nascimento da clínica. Rio de Janeiro: Forense Universitária, 1994.

FOUCAULT, M. Vigiar e punir. Petrópolis: Vozes, 1995a.

RIAEE - Revista Ibero-Americana de Estudos em Educação, Araraquara, v. 14, n. esp. 4, p. 2032-2045, dez., 2019. E-ISSN: $1982-5587$. 
FOUCAULT, M. O sujeito e o poder. In: DREYFUS, H.; RABINOW, P. Michel Foucault. Uma trajetória filosófica. Rio de Janeiro: Forense Universitária, p. 231-149, 1995b.

FOUCAULT, M. Omnes et singulation. Hacia uma critica de la razón política. In: FOUCAULT, M. Que és la ilustración? Córdoba: Alción, p. 17-66, 1996.

FOUCAULT, M. Arqueologias do saber. Rio de Janeiro: Forense Universitária, 1997.

FOUCAULT, M. O Uso dos prazeres. In: FOUCAULT, M. História da sexualidade. Rio de Janeiro: Graal, v. 2, 1998.

KECHINKIAN, A. Os filósofos e a educação. Lisboa: Colibri, 1993.

LAROSA, J. Algumas notas sobre experiência y sus lenguajes. In: BARBOSA, R. L. L. (org.) Trajetórias e perspectives da formação de educadores. S.P.: Ed. UNESP, 2004.

LAROSA, J. Linguagem e Educação depois de Babel. Trad.: Cynthia Farina. Belo Horizonte: Autêntica, 2004.

LYOTARD, J-F. Lecturas de infancia. Buenos Aires: EUDEBA, 1997.

LYOTARD, J-F. O inumano: considerações sobre o tempo. São Paulo: Estampa, 1997a.

LYOTARD, J-F. A condição pós-moderna. São Paulo: José Olympio, 2000.

\section{Como referenciar este artigo}

SILVA, Anilde Tombolato Tavares da; BITTENCOURT, Cândida Alayde de Carvalho; OLIVEIRA, Marta Regina Furlan de. A experiência da infância entre os dilemas da educação moderna e o empobrecimento do trabalho docente. Revista Ibero-Americana de Estudos em Educação, Araraquara, v. 14, n. esp. 4, p. 2032-2045, dez., 2019. E-ISSN: 1982-5587. DOI: https://doi.org/10.21723/riaee.v14iesp.4.12926

Data de submissão: 25/06/2019

Data de aceite: 29/07/2019

Data de publicação: 01/09/2019 